\title{
ANALYSIS OF THE APPARENT BIPHASIC AXONAL TRANSPORT KINETICS OF FUCOSYLATED GLYCOPROTEINS ${ }^{1}$
}

\author{
JEFFRY F. GOODRUM ${ }^{2}$ AND PIERRE MORELL ${ }^{3}$ \\ Biological Sciences Research Center and Department of Biochemistry, University of North Carolina, Chapel Hill, \\ North Carolina 27514
}

Received August 29, 1983; Revised February 1, 1984; Accepted February 3, 1984

\begin{abstract}
Following intraocular injection of $\left[{ }^{3} \mathrm{H}\right]$ fucose, which labels many glycoproteins of retinal ganglion cells, the accumulation of transported radioactivity arriving at the superior colliculus (nerve terminals) peaks within a few hours and decays with a time course of hours. Then, over a period of several days, radioactivity again accumulates at the superior colliculus and then decays with a halflife of days. The second peak also represents fast transported material since it occurs almost simultaneously along the optic nerve and tract as well as at the nerve endings. Such data have been interpreted as evidence for both a group of rapidly released, rapidly transported glycoproteins (first peak) and a group of slowly released but rapidly transported glycoproteins (second peak). We investigated this supposition by studying in more detail the metabolism of some individual fucosylated proteins in both the retina and superior colliculus. We noted that much of the radioactivity incorporated in fucosylated glycoproteins at the retina was rapidly metabolized (with a turnover on the order of hours), while the remainder of the fucosylated moieties had a metabolic half-life on the order of days. This was also true of the metabolic behavior of several individual glycoproteins, selected for study because they are major components of the group committed to transport and accumulating in two waves at the superior colliculus. In other experiments we injected $\left[{ }^{35} \mathrm{~S}\right]$ methionine intraocularly and examined the metabolism in the retina and the kinetics of transport to the superior colliculus of the peptide backbone of these same individual proteins. In contrast to the two waves of accumulation of radioactivity from $\left[{ }^{3} \mathrm{H}\right]$ fucose, accumulation of radioactivity of the peptide backbone of the same glycoproteins was monophasic.

Our explanation of these data involves the presence of two types of fucose moieties on the peptides. One group of fucose moieties is labile and is lost from the peptide backbone over a period of hours. Other fucose moieties are approximately as metabolically stable as the peptide backbones to which they are attached. The actual peptide backbones of the glycoproteins are committed to rapid transport over a period of several days. Thus, the first (and most prominent) peak of transported radioactivity in $\left[{ }^{3} \mathrm{H}\right]$ fucosylated glycoproteins does not represent a discrete phase of transport but, rather, is the summation of kinetics of gradual arrival of proteins and the rapid drop in their specific radioactivity as the more labile moieties of $\left[{ }^{3} \mathrm{H}\right]$ fucose are lost. In contrast, accumulation at the superior colliculus of the more metabolically stable $\left[{ }^{3} \mathrm{H}\right]$ fucose moiety coincides with the accumulation of the actual peptide backbone; there is a period of several days during which the pool of labeled peptides is slowly committed to rapid transport. Analysis of the kinetics of turnover of fucose on proteolytic cleavage products of transported glycoproteins suggested that, at least in one case, the rapidly and slowly metabolized moieties are on different carbohydrate chains of the same peptide.
\end{abstract}

Rapid axonal transport can be studied by presenting a specific radioactive precursor to the cell body and then

\footnotetext{
${ }^{1}$ This work was supported by United States Public Health Service Grants NS11615 and HD 03110.

${ }^{2}$ Present address: Biology Department, North Carolina Central University, Durham, NC 27707.

${ }^{3}$ To whom correspondence should be addressed.
}

determining the time of appearance of biosynthesized radioactive macromolecules at various points on their way to the nerve terminals. The rapid component of axonal transport contains predominantly membrane constituents which are thought to be transported in vesicular or other membranous structures (Grafstein and Forman, 1980; Tytell et al., 1981; Baitinger et al., 1982). Radioactivity associated with a particular membrane 
protein (Willard et al., 1974; Tytell et al., 1981) or lipid (Haley et al., 1979: Toews et al., 1979; Toews and Morell, 1981 ) initially accumulates in the nerve endings; this is followed by a decay phase when catabolism and other processes removing the protein or lipid from the nerve ending exceed the ever diminishing accumulation of radioactivity.

However, a complication occurs when data from studies using glycoprotein precursors are considered. Following intraocular injection of $\left[{ }^{3} \mathrm{H}\right]$ fucose in rodents, radioactivity in glycoproteins arriving at the superior colliculus is detectable within $3 \mathrm{hr}$ (rapid transport) and peaks within a day. There is then a decline over the next day or two, and then accumulation of radioactivity resumes until there is another peak at about a week following injection (Specht and Grafstein, 1977; Goodrum et al., 1979; Goodrum and Morell, 1982). The material in the second peak is also rapidly transported since the rise in radioactivity occurs almost simultaneously along the optic nerve and optic tract as well as at the superior colliculus. Similar observations have been made in other nerve tracts of the rat (Padilla and Morell, 1980), and replotting of the data of Bennet et al. (1973) suggests biphasic accumulation of fucosylated glycoprotein in the chick ciliary ganglion.

The molecular weight distribution of labeled glycopeptides and their partition into particulate and soluble fractions are similar at both accumulation peaks (Goodrum et al., 1979; Goodrum and Morell, 1982). Thus, the accumulation of radioactivity in many of the individual glycoproteins at the superior colliculus appeared to be biphasic in contrast to the expectation, in the simple case, of a monophasic accumulation and decline of radioactivity. To resolve this discrepancy, we followed the lead of Specht and Grafstein (1977) in interpreting such data in terms of a model of a glycoprotein-containing vesicular or membranous structure being partitioned into two pools, one rapidly released and rapidly transported and the other slowly released but rapidly transported (Goodrum and Morell, 1982).

A prediction to be made from the above model is that the rapidly transported fucosylated proteins should show a biphasic accumulation when labeled with a radioactive amino acid. Therefore, we have re-examined this problem by analyzing the synthesis in the retina, transport to and accumulation in the superior colliculus, and metabolic turnover in both tissues, of the $\left[{ }^{3} \mathrm{H}\right]$ fucose moiety and the $\left[{ }^{35} \mathrm{~S}\right]$ methionine-labeled peptide backbone of individual peptides separated by two-dimensional gel electrophoresis. The results did not support the model of two pools of transported proteins. Instead, the biphasic accumulation of the $\left[{ }^{3} \mathrm{H}\right]$ fucose radioactivity in the superior colliculus results from the summation of a gradual accumulation of the rapidly transported glycoproteins at the nerve ending (committed to rapid transport over a period of days from a single pool of peptides in the retina) and a biphasic turnover of the fucose moieties of those glycoproteins.

\section{Materials and Methods}

Long-Evans rats, 30 to 60 days of age, bred from Charles River (Wilmington, MA) stock were used. L- $\left[5,6-{ }^{3} \mathrm{H}\right]$ Fucose $(60 \mathrm{Ci} / \mathrm{mmol}), \mathrm{L}-\left[{ }^{35} \mathrm{~S}\right]$ methionine $(800$ $\mathrm{Ci} / \mathrm{mmol}$ ), and Enhance were obtained from New England Nuclear Corp. (Boston, MA). Chymotrypsin was from Sigma Chemical Co. (St. Louis, MO). Pharmalyte 3-10 ampholites were obtained from Pharmacia Fine Chemicals (Piscataway, NY). X-ray film (XAR-5) and processing chemicals were from Eastman Kodak (Rochester, NY). All other chemicals were reagent grade.

Precursor injection and tissue preparation. Radioactive precursor was injected into the left vitreous chamber in $4 \mu \mathrm{l}$ of $0.9 \% \mathrm{NaCl}$ as previously described (Goodrum et al., 1979). Animals were killed at $8 \mathrm{hr}$ (first wave peak), 1 day, 2 days, 1 days, and 7 days (second wave peak) following injection, and the left retinas and right superior colliculi were removed. Tissues were homogenized in 0.2 $\mathrm{ml}$ of water, lyophilized, and frozen at $-70^{\circ} \mathrm{C}$ until used.

Gel electrophoresis. For two-dimensional gel electrophoresis, lyophilized tissues were solubilized in $100 \mu \mathrm{l}$ of $5 \%$ Nonidet P-40 (Particle Data Labs, Elmhurst, IL), 8 M urea, $5 \% \quad \beta$-mercaptoethanol, and 5\% Pharmalyte 310 by sonication in an ultrasonic cleaning water bath (Branson). The samples were then centrifuged for $5 \mathrm{~min}$ at $7000 \times g$ in a Fisher model 59 centrifuge. Ten microliters of retina and $40 \mu \mathrm{l}$ of superior colliculus supernatants were used for nonequilibrium $\mathrm{pH}$ gradient electrophoresis (NEPHGE) at $400 \mathrm{~V}$ for $4 \mathrm{hr}$, performed according to the method of O'Farrell et al. (1977). The second-dimensional separation was on 7 to $15 \%$ linear gradient polyacrylamide slab gels run at $25 \mathrm{~mA} /$ gel until the tracking dye reached the bottom of the gel. All $\left[{ }^{3} \mathrm{H}\right]$ fucose- and $\left[{ }^{35} \mathrm{~S}\right]$ methionine-labeled samples from the same time points for each tissue were subjected to electrophoresis simultaneously to facilitate matching of bands and spots. One-dimensional gradient gel electrophoresis was performed as previously described (Goodrum and Morell, 1982).

Peptide mapping. Peptide mapping of transported glycoproteins was performed by a slight modification of the method of Cleveland et al. (1970). Labeled proteins were initially separated on $7.5 \%$ polyacrylamide gels (Goodrum et al., 1979). These gels were sliced into $1.1-\mathrm{mm}$ slices, and the proteins were eluted from each slice for $24 \mathrm{hr}$ at room temperature in $1 \mathrm{ml}$ of electrophoresis buffer. Aliquots from each gel slice were counted for radioactivity, and eluates from gel slices corresponding to single radioactivity peaks were pooled. In some cases, corresponding peaks from several superior colliculus gels were pooled. One-fifth volume of $100 \%$ trichloroacetic acid and 5\% phosphotungstic acid was added to the pooled samples at room temperature, and the samples were placed on ice for $1 \mathrm{hr}$. The precipitated proteins were collected by centrifugation and washed with ethanol and then diethyl ether. The pellet was dissolved in 200 $\mu \mathrm{l}$ of sample buffer (Cleveland et al., 1977) and was incubated for $30 \mathrm{~min}$ at $37^{\circ} \mathrm{C}$ with varying amounts of chymotrypsin. $\beta$-Mercaptoethanol and SDS were then added to final concentrations of $10 \%$ and $2 \%$, respectively, and the samples were boiled for $2 \mathrm{~min}$. The peptides in the digested samples were separated on $15 \%$ polyacrylamide gels. These gels were sliced, and radioactivity distribution was determined as described previously (Goodrum et al., 1979). 


\section{Results}

Time course of transport. Following intraocular injection, retinal incorporation peaks within the first few hours for both precursors (Goodrum et al., 1979; Blaker et al., 1981), and thereafter radioactivity in the retina declines (Fig. 1A). With both precursors, transported radioactivity arrives in the superior colliculus within 3 hr (Fig. 1B). It is noteworthy that (except for a temporal delay in accumulation corresponding to the time required for rapid transport), the peak of accumulation and the time course of initial decline of radioactivity in fucosylated glycoproteins in the superior colliculus follow a pattern remarkably similar to that in the retina. The continued accumulation of $\left[{ }^{3} \mathrm{H}\right]$ fucose-labeled material exhibits the biphasic pattern described above. In contrast, the accumulation of $\left[{ }^{35} \mathrm{~S}\right]$ methionine-labeled material in the superior colliculus is multiphasic due to both the arrival and heterogeneous turnover of each of the different transport rate components (Fig. $1 B$ ) (see also Karlsson and Sjostrand, 1971; Blaker et al., 1981).

Peptide composition of synthesized and transported proteins. Fluorographs of one-dimensional gels of retina and superior colliculus samples at $8 \mathrm{hr}$ to 7 days after injection of either $\left[{ }^{3} \mathrm{H}\right]$ fucose or $\left[{ }^{35} \mathrm{~S}\right]$ methionine are shown in Figure 1. In many cases the retinal $\left[{ }^{3} \mathrm{H}\right]$ fucoselabeled polypeptides correspond to relatively minor components of the more complex pattern of $\left[{ }^{35} \mathrm{~S}\right]$ methioninelabeled peptides. The glycoprotein bands tend to be broader than most of the $\left[{ }^{35} \mathrm{~S}\right]$ methionine-labeled gel bands, presumably due to the heterogeneity of glycosylation. The gel pattern of $\left[{ }^{3} \mathrm{H}\right]$ fucose-labeled glycoproteins in the superior colliculus is similar to that in the retina. This is true at all times studied (Fig. 1B). Many, although not all, of the glycoproteins are transported in quantities roughly proportional to their synthesis (most of the bands prominent in the gel of retinal proteins are prominent also in the superior colliculus). In contrast, the gel pattern of $\left[{ }^{35} \mathrm{~S}\right]$ methionine-labeled transported proteins arriving in the superior colliculus at $8 \mathrm{hr}$ is very simple compared to that in the retina. Although this may be partly an artifact of the film exposure (longer exposures would reveal minor bands), it is clear that the quantitative distribution of the transported $\left[{ }^{35} \mathrm{~S}\right]$ methionine-labeled proteins is very different from the population of proteins originally labeled in the retina.

At early time points, the gel pattern of the $\left[{ }^{3} \mathrm{H}\right]$ fucoselabeled protein is similar to the distribution of label from $\left[{ }^{35} \mathrm{~S}\right]$ methionine, suggesting that the majority of rapidly transported proteins are glycoproteins (see also Tytell et al., 1980). This similarity is not found at the later time points. While the $\left[{ }^{3} \mathrm{H}\right]$ fucose-labeled glycoprotein pattern does not change with increasing time after injection (no new bands appear), the $\left[{ }^{35} \mathrm{~S}\right]$ methionine-labeled pattern changes in a complex fashion at later times, as some labeled bands disappear while new ones appear (presumably representing arrival of the slower components of transport in the superior colliculus).

Two-dimensional gel electrophoresis of labeled retina and superior colliculus was carried out at the same time points as shown in Figure 1. Results at $8 \mathrm{hr}$ and at 7 days after injection of $\left[{ }^{3} \mathrm{H}\right]$ fucose are shown in Figure 2.
Proteins forming single, broad bands on the one-dimensional gels were resolved into families of spots forming slightly diagonal bands on the two-dimensional gels. This pattern is a feature common to glycoproteins separated on two-dimensional gels (Baumann and Doyle, 1979; Wenthold and McGarvey, 1982). Most of the labeled glycoproteins of the optic pathway have acidic isoelectric points, the 28,000 -dalton protein being conspicuous by its more basic isoelectric point. In the nonequilibrium system, it is the most rapidly migrating labeled glycoprotein (see Fig. 2), and in a pH 4 to 8 isoelectric focusing gel it remains at the basic end of the gel (not shown). There is heterogeneity in the metabolic turnover of the label from $\left[{ }^{3} \mathrm{H}\right]$ fucose since many of the retina peptides that were well labeled at $8 \mathrm{hr}$ were among the most poorly labeled at 1 to 2 days and were nearly undetectable by 7 days.

By $8 \mathrm{hr}$ the two-dimensional gels of superior colliculus already contain almost all of the major $\left[{ }^{3} \mathrm{H}\right]$ fucose-labeled peptides present in the retinal gels (Fig. 2). At no later time were any new labeled proteins identified on the gels of the superior colliculus. From $8 \mathrm{hr}$ to 7 days, the gel pattern became progressively simpler in a manner roughly parallel to the results from gels of retina. This trend toward a less complex labeling pattern continues even during the arrival of the second wave (4 to 7 days) when total radioactivity is increasing in the superior colliculus (i.e., no new proteins are arriving). At 7 days after injection, the two-dimensional gel patterns of transported proteins in the superior colliculus still resemble the corresponding retinal gel, not only qualitatively, but in the relative quantitative relationship of the proteins. Note that this similarity between superior colliculus and retina is not necessarily expected since there is no a priori reason to suggest, even if exported glycoproteins are representative of those in the cell body, that the concentration of ganglion cell proteins would mimic that of other types of cells in the retina. These observations suggest that those transported glycoproteins poorly represented in the gels of second-wave material are those whose fucose moieties turn over rapidly in the retina and, therefore, are poorly labeled by the time they are committed to transport.

Fluorographs of two-dimensional gels of $\left[{ }^{35} \mathrm{~S}\right]$ methionine-labeled retina and superior colliculus at $8 \mathrm{hr}$ and at 7 days after injection are shown in Figure 3. In contrast to the two-dimensional gels of $\left[{ }^{3} \mathrm{H}\right]$ fucose-labeled retinal glycoproteins, the two-dimensional gels of $\left[{ }^{35}\right.$ S]methionine-labeled retinal proteins were much more complex than the corresponding one-dimensional gels, hundreds of methionine-labeled proteins being resolved over a wide range of $\mathrm{pH}$ (Fig. 3). This is not unexpected since presumably more proteins contain methionine than contain fucose. Most of these labeled proteins are seen as distinct spots rather than more diffuse diagonal bands, as in the case of the glycoproteins. The $\left[{ }^{35} \mathrm{~S}\right]$ methionine-labeled proteins in the superior colliculus at $8 \mathrm{hr}$ after injection are confined primarily to the acidic portion of the gel, and many of the more prominent spots correspond to the $\left[{ }^{3} \mathrm{H}\right]$ fucose-labeled glycoproteins present at $8 \mathrm{hr}$ (Fig. 4). At later times this pattern changes due to the appearance of new $\left.{ }^{35} \mathrm{~S}\right] \mathrm{methionine-labeled} \mathrm{spots.} \mathrm{At} \mathrm{all} \mathrm{times} \mathrm{stud-}$ 
A. RETINA

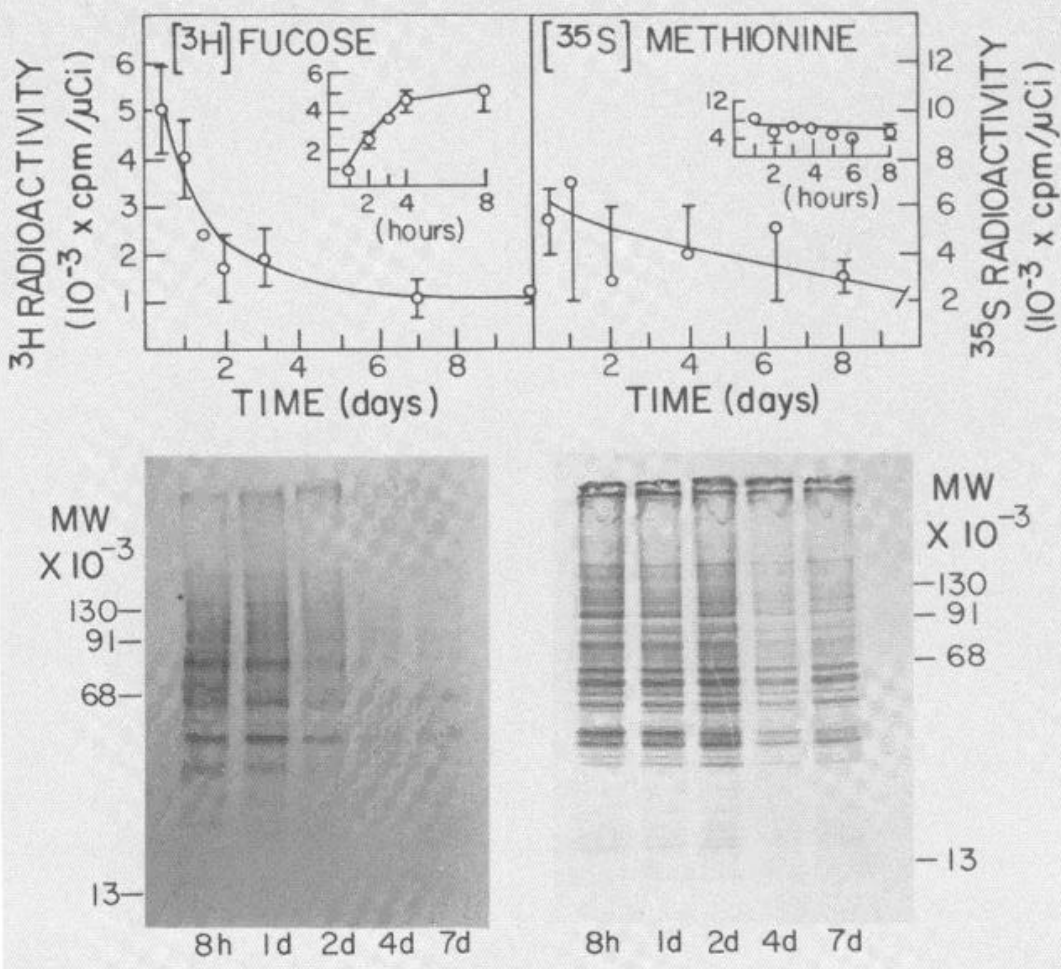

B. SUPERIOR COLLICULUS
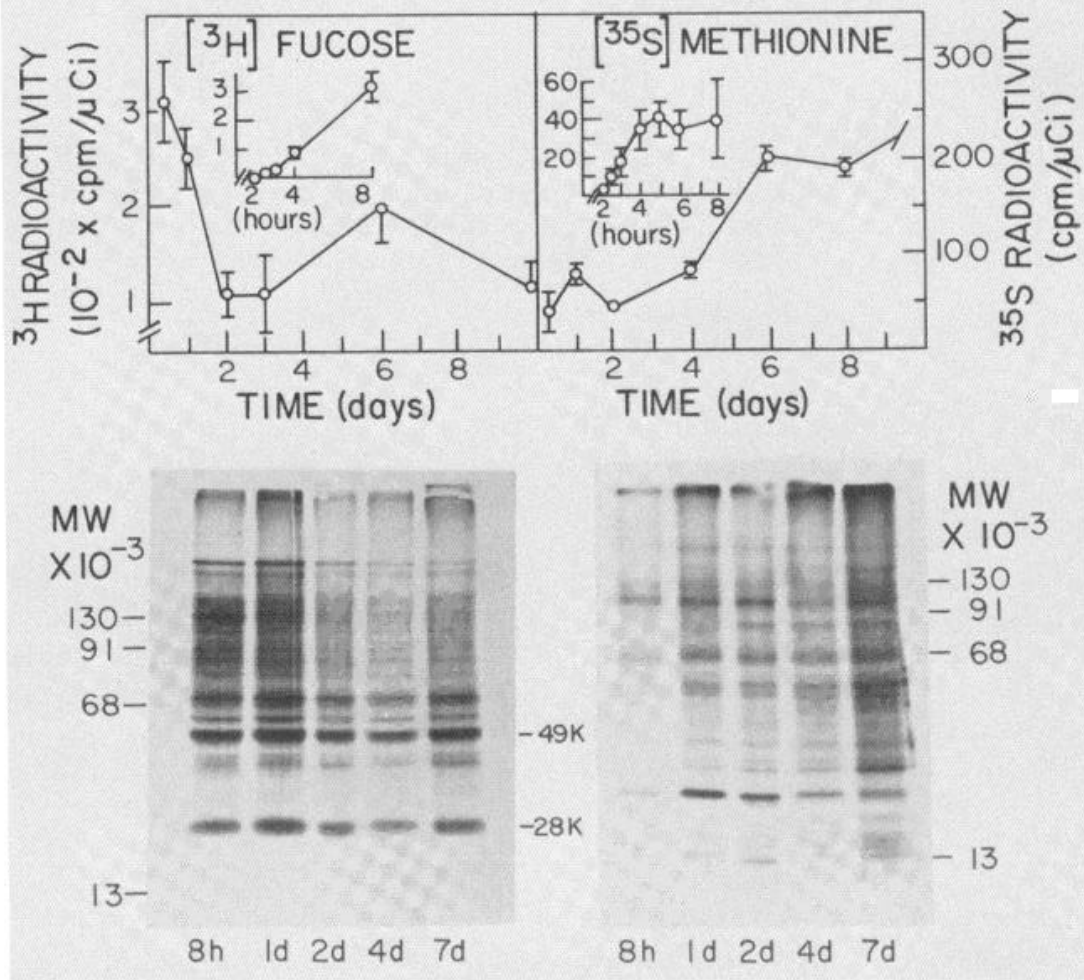

Figure 1. Time course and one-dimensional gel electrophoretic peptide composition of synthesized and transported proteins following intraocular injection of $\left[{ }^{3} \mathrm{H}\right]$ fucose or $\left[{ }^{35} \mathrm{~S}\right]$ methionine. Data are expressed as counts per minute incorporated per microcurie of precursor injected. $A$, Time course of retinal incorporation and turnover. $B$, Time course of transport in the superior colliculus. Data points are means $\pm \operatorname{SEM}(n=4$ to 7$)$ of pooled data from this and previous reports (Goodrum and Morell, 1982). For each time point equal amounts of protein were applied to the gels. 


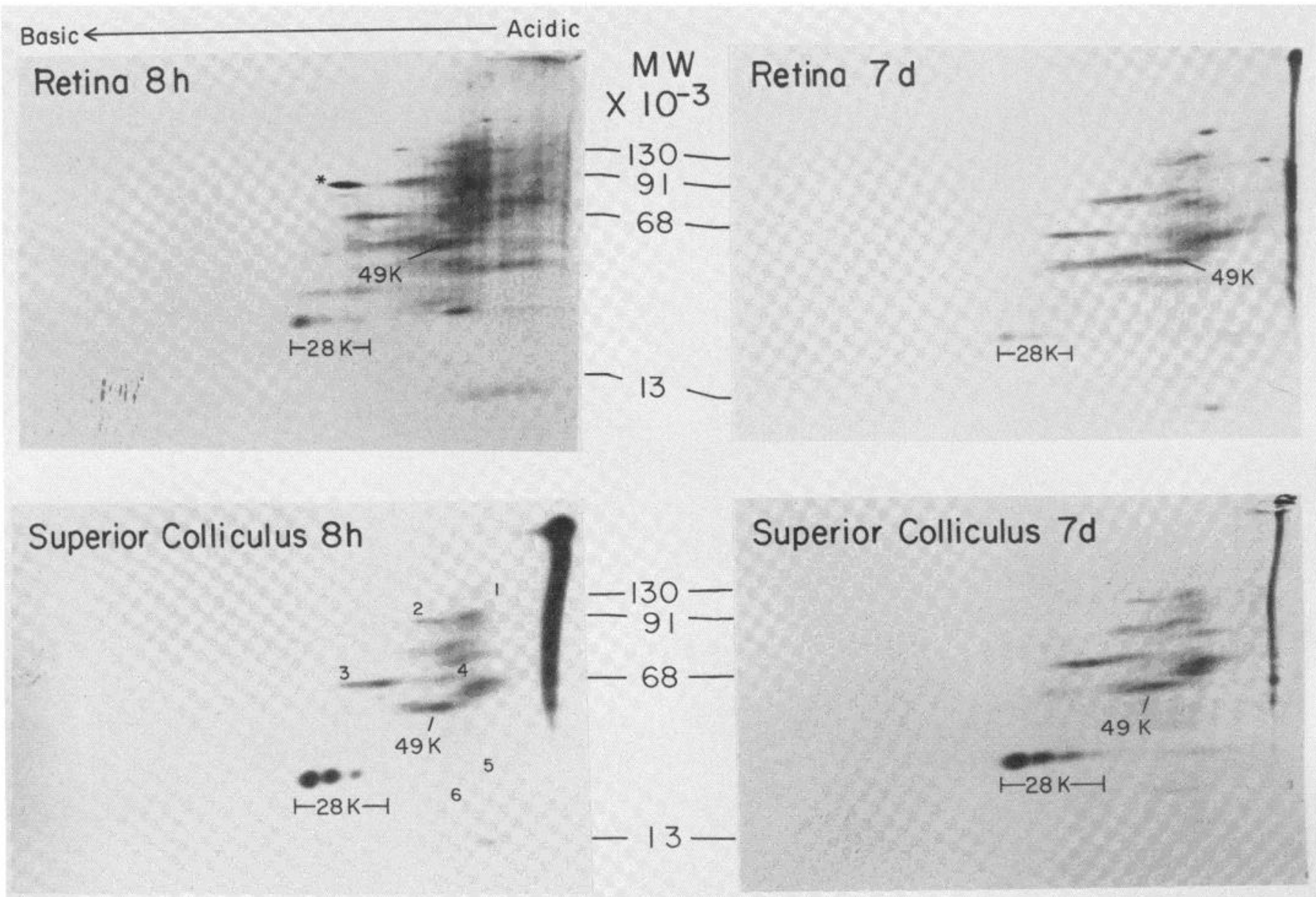

Figure 2. Fluorographs of two-dimensional gels of retina and superior colliculus $8 \mathrm{hr}$ and 7 days after intraocular injection of $400 \mu \mathrm{Ci}$ of $\left[{ }^{3} \mathrm{H}\right]$ fucose. Samples were prepared and gels were run as described in the text. The acidic end of the gel is to the right, and the $49,000-(49 K)$ and 28,000 -dalton $(28 K)$ proteins are indicated. The asterisk marks a retinal glycoprotein which is absent from the retina by 1 to 2 days and does not appear in the superior colliculus. Numbered spots are for comparison with Figures 3 and 4 .

ied, the retinal gel pattern remains more complex than that in the superior colliculus. This is in contrast to the results obtained with the $\left[{ }^{3} \mathrm{H}\right]$ fucose-labeled glycoproteins; the $\left[{ }^{35} \mathrm{~S}\right]$ methionine results demonstrate that the population of proteins transported to the nerve endings of retinal ganglion cells is a subclass of the total protein population synthesized by the many cells of the retina.

Transport time course of individual glycoproteins. Two of the major transported glycoproteins have $M_{\mathrm{r}}=49,000$ and 28,000 (see Figs. $1 B$ and 2). Both of these $\left[{ }^{3} \mathrm{H}\right]$ fucose-labeled glycoproteins exhibit a biphasic accumulation in the superior colliculus (see Fig. $1 B$ and for more detail, Goodrum and Morell, 1982). To estimate the transport time course for the peptide backbone of these glycoproteins, the corresponding $\left[{ }^{35} \mathrm{~S}\right]$ methionine-labeled proteins on the two-dimensional gels (see Fig. 4) were cut out, and radioactivity was determined by liquid scintillation counting (Fig. 5). In contrast to the labeled fucose moieties, the labeled peptide backbones of these two glycoproteins accumulate in the superior colliculus for several days. The $\left[{ }^{35} \mathrm{~S}\right]$ methionine label in other glycoproteins also appears to persist for many days.

While the backbones of the glycoproteins accumulate over several days, many other $\left[{ }^{35} \mathrm{~S}\right]$ methionine-labeled proteins in the superior colliculus accumulate and turn over more rapidly. The accumulation of the major transported protein (24,000 daltons) peaks between 1 and 2 days and then declines (see Fig. 3 and Wagner et al., 1979; Kelly et al., 1980). Another transported protein (about 100,000 daltons) is well labeled at $8 \mathrm{hr}$ but absent from the fluorographs by 1 day after injection (see Fig. 3).

Peptide mapping of fucosylated glycoproteins. Our present results and those we have previously reported suggest that the fucose moieties on at least several individual transported glycoproteins turn over with biphasic kinetics (Goodrum and Morell, 1982). We postulated that this may be due to the presence, on the same protein, of several fucose moieties, perhaps with different metabolic half-lives. These fucose moieties could be on the same or different carbohydrate chains of the protein. If the latter were the case, proteolytic cleavage might form peptides bearing carbohydrate chains containing only the rapidly or the slowly turning over fucose moieties. To test this hypothesis, the 49,000 -dalton $\left[{ }^{3} \mathrm{H}\right]$ fucose-labeled peak was excised from one-dimensional gels of both retina and 


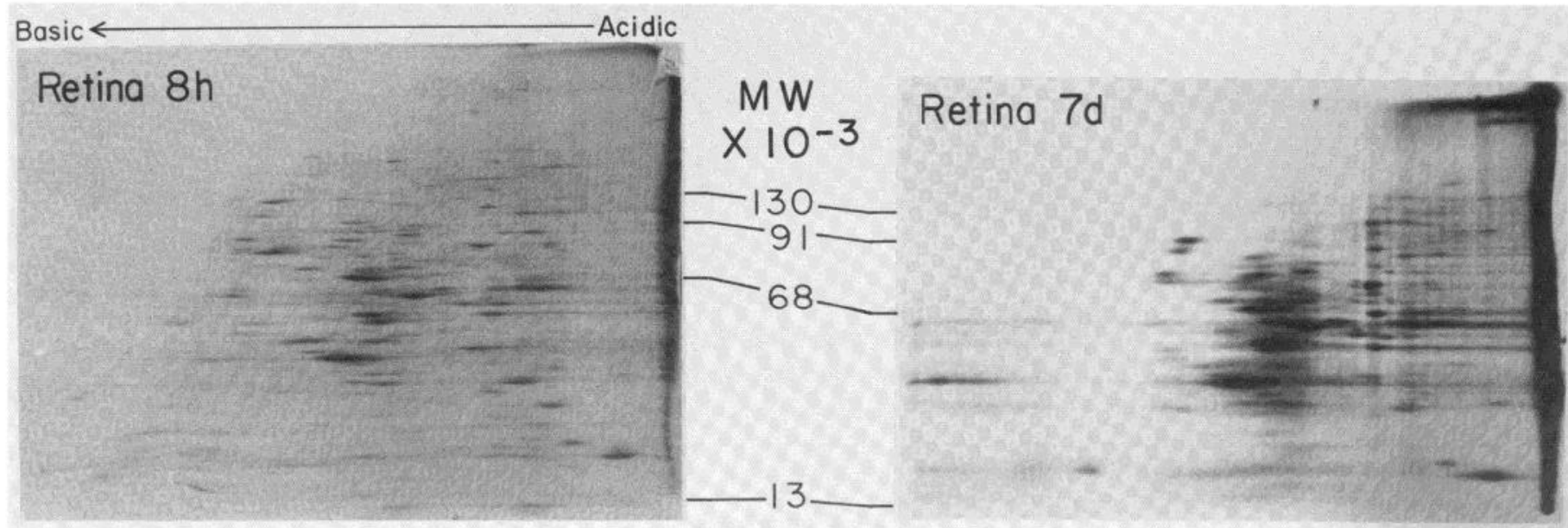

\section{Superior Colliculus $8 \mathrm{~h}$}

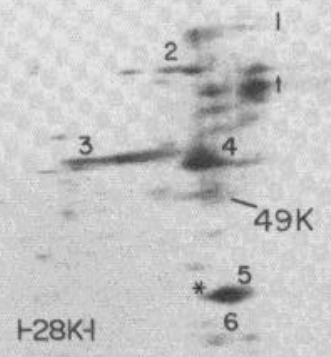

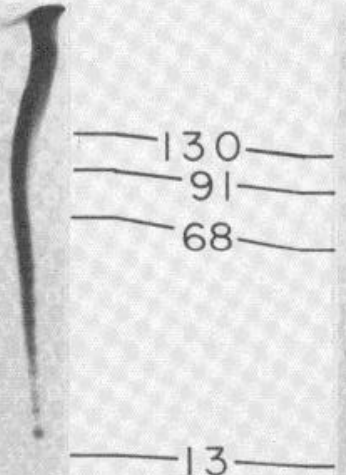

Figure 3. Fluorographs of two-dimensional gels of retina and superior colliculus $8 \mathrm{hr}$ and 7 days after intraocular injection of $400 \mu \mathrm{Ci}$ of $\left[{ }^{35} \mathrm{~S}\right]$ methionine. The transported $49,000-(49 K)$ and 28,000 -dalton $(28 K)$ proteins are indicated in the superior colliculus gels. These proteins cannot be resolved in the much more complex pattern on the retinal gels. The asterisk marks the major, 24,000-dalton, transported protein. The dagger indicates a very rapidly turning over transported protein which is present at $8 \mathrm{hr}$ but absent by 1 day. Numbered spots are for comparison with Figures 2 and 4 .

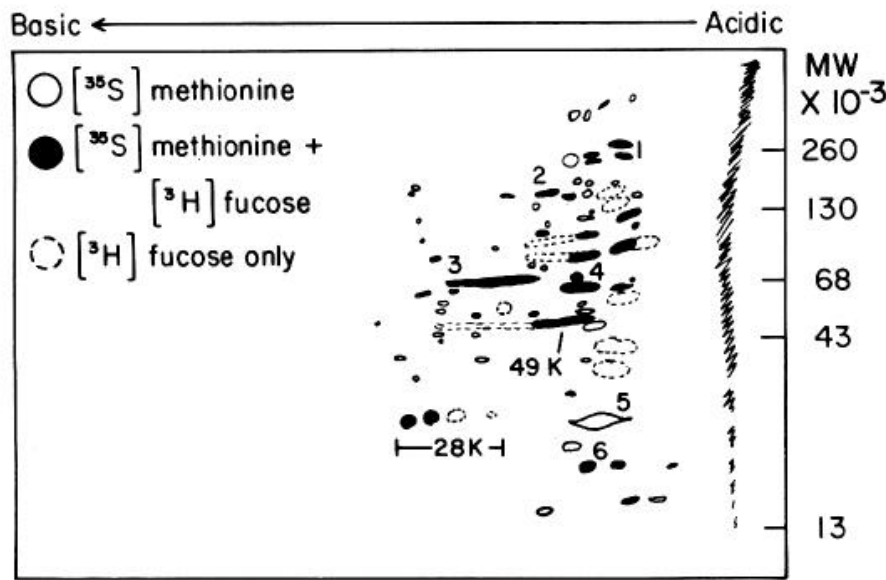

Figure 4. Comparison of fluorographs of $\left[{ }^{3} \mathrm{H}\right]$ fucose- and $\left[{ }^{35} \mathrm{~S}\right]$ methionine-labeled transported proteins in the superior colliculus $8 \mathrm{hr}$ after intraocular injection. This composite was drawn by overlaying the fluorographs from the 8 -hr time points in Figures 2 and 3. Numbered spots are for comparison with Figures 2 and 3. The protein indicated by dashed lines had so high a ratio of fucose to methionine that the $\left[{ }^{35} \mathrm{~S}\right]$ methionine presumably present could not be detected on fluorographs exposed to allow resolution of most proteins. of superior colliculus at $8 \mathrm{hr}, 1$ day, 2 days, and 5 days after injection (the two-dimensional gels indicated that this band is nearly homogeneous; see Fig. 2), and the eluted proteins were subjected to limited proteolysis by chymotrypsin. The resulting peptide fragments were separated on $15 \%$ polyacrylamide gels, and the distribution of radioactivity was determined. In Figure 6 the distribution of radioactivity among the peptide fragments is plotted as a percentage of the total radioactivity in the digested sample. Plotted this way peptide fragments with rapidly turning over fucose will, with time, contain progressively smaller percentages of the total radioactivity (these peaks will diminish, relative to peaks corresponding to fragments with slow turnovers). In both the retina and superior colliculus, the same labeled peptide fragments were produced at each time point from $8 \mathrm{hr}$ to 5 days after injection (Fig. 6 contrasts results from the 8$\mathrm{hr}$ and 5-day time points). However, the distribution of radioactivity among these peptides changed with time after injection, indicating that there are at least two major rates of turnover for the fucose moieties of this glycoprotein which correspond to fucose moieties localized to separate peptide fragments. We suggest that the bulk of the rapidly turning over fucose moieties are on 


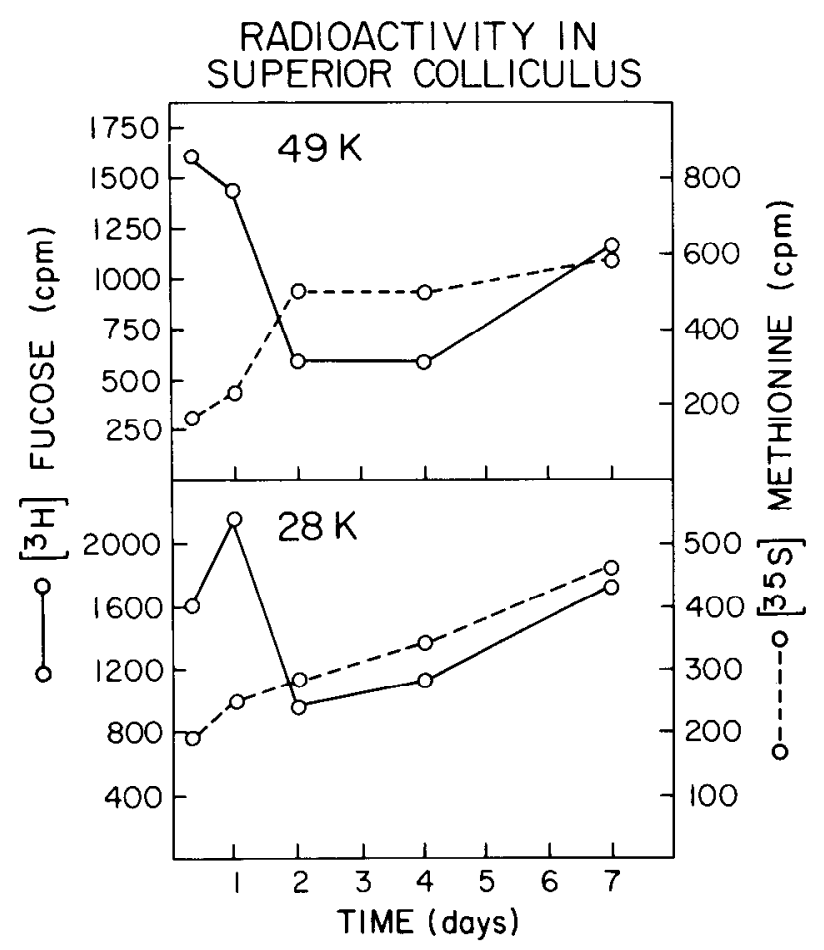

Figure 5. Time course of accumulation of $\left[{ }^{3} \mathrm{H}\right]$ fucose and $\left[{ }^{35} \mathrm{~S}\right]$ methionine radioactivity in the $49,000-(49 K)$ and $28,000-$ dalton $(28 K)$ proteins in the superior colliculus. Appropriate regions were excised from the two-dimensional gels, and radioactivity was determined by liquid scintillation counting.

carbohydrate chains which are distinct from those containing the more metabolically stable fucose moieties.

\section{Discussion}

Detailed studies of the accumulation of transported $\left[{ }^{3} \mathrm{H}\right]$ fucose-labeled glycoproteins at nerve endings have revealed two phases of accumulation separated by a period of days (this report and Specht and Grafstein, 1977; Goodrum et al., 1979; Goodrum and Morell, 1982). The first phase of accumulation has been generally interpreted as representing glycoproteins which were rapidly committed to axonal transport and which turned over rapidly at the nerve endings. This interpretation implied that the second phase represent a separate pool of glycoproteins with different somal processing and different metabolism. We thought that this might be expected if two different types of glycoproteins were involved; however, we failed to find any differences in composition or subcellular distribution for the transported material in the two phases (Goodrum and Morell, 1982). In addition, the original model is complicated by the data indicating simultaneous transport of different membrane constituents (Abe et al., 1973). Also, studies using high resolution separation techniques do not provide any data suggestive of biphasic transport behavior of any membrane constituents (Willard et al., 1974; Haley et al., 1979; Toews et al., 1979; Tytell et al., 1981) (with the possible exception of Fodrin, a protein found to be transported at more than one rate (see Baitinger et al., 1982)).

In trying to account for the discrepancies, we realized

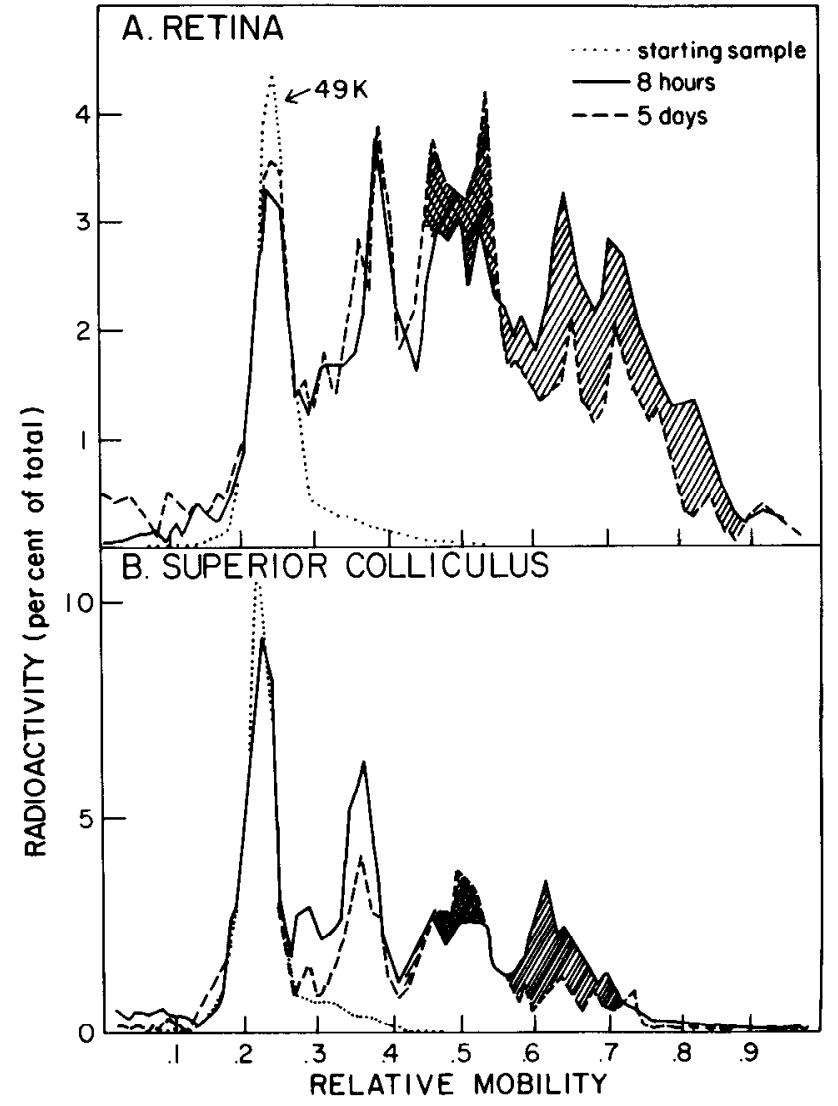

Figure 6. Peptide maps of the 49,000-dalton (49K) protein from retina and superior colliculus at $8 \mathrm{hr}$ and 5 days after injection. Chymotrypsin digestion and gel electrophoresis were as described in the text. Shaded regions illustrate the changes from $8 \mathrm{hr}$ to 5 days. The hatched and cross-hatched regions show areas of decrease and increase in relative labeling, respectively. The dotted line indicates sample incubated without any chymotrypsin present.

that it was not necessary to assume that the turnover of labeled fucose moieties represented that of the entire glycoprotein molecule. In fact, it has recently been observed, for rat liver and hepatocyte cultures, that the fucose moieties of plasma membrane glycoproteins may turn over more rapidly than the peptide backbones (Kreisel et al., 1980; Baumann et al., 1983; see Baumann and Doyle, 1982, for a review). Our present studies indicate that the biphasic accumulation of radioactivity is not due to two waves of transport of material but results from the heterogeneous metabolic properties of fucose moieties on individual glycoproteins. This conclusion is based on three observations.

First, the initial accumulation and decline of transported radioactivity in the superior colliculus mimics the incorporation and initial decay time course of the retina (see "Results" and Fig. 1). In addition, following the second phase of accumulation in the superior colliculus, the subsequent decline of total radioactivity, as well as the metabolic decay noted for certain individual glycoproteins, is similar to the second phase of the biphasic decay kinetics in the retina. This result is better supported by data from a previous publication (Goodrum and Morell, 1982) which includes a more detailed time course (multiple observations at five time points) allow- 
ing for a determination of the turnover times during the second phase as about 8 days for both retina and superior colliculus. These data suggest that the initial pattern of accumulation and both periods of decline of radioactivity in the superior colliculus are dominated by the metabolic properties of the glycoproteins, not by their transport kinetics.

Second, when the accumulation of radioactivity in the superior colliculus from corresponding spots of two-dimensional gels labeled with either $\left[{ }^{3} \mathrm{H}\right]$ fucose or $\left[{ }^{35} \mathrm{~S}\right]$ methionine are compared, the $\left[{ }^{3} \mathrm{H}\right]$ fucose radioactivity follows a biphasic pattern while the $\left.{ }^{35} \mathrm{~S}\right]$ methionine radioactivity follows a monophasic one. Thus, the polypeptide backbones of at least two glycoproteins accumulate monophasically over a period of days.

Third, at least one individual glycoprotein in both retina and superior colliculus was found to contain multiple fucose-containing carbohydrate chains with differing turnover rates. Although this is probably the case for many of the transported glycoproteins, it is possible either that some have only the rapidly metabolized fucose moieties or that the entire peptide turns over with a short half-life, accounting for the rapid disappearance of a few fucosylated proteins from the retina (see Fig. 2). However, many of the glycoprotein backbones do appear to be relatively stable metabolically, as compared to the rapid turnover of a number of the rapidly transported $\left[{ }^{35} \mathrm{~S}\right]$ methionine-labeled proteins (see "Results" and Wagner et al., 1979). This observation is consistent with recent hypotheses that the carbohydrate moieties contribute directly to the metabolic stabilization of membrane glycoproteins (see Olden et al., 1982, for a review).

Therefore, it appears that the two waves of accumulation of transported $\left[{ }^{3} \mathrm{H}\right]$ fucose radioactivity in (individual) glycoproteins in the superior colliculus are due to the summation of a gradual accumulation of transported glycoproteins and the biphasic turnover of the fucose moieties on these glycoproteins. Figure 7 illustrates theoretical curves demonstrating how this can come about. A combination of a prolonged release from the retina and gradual accumulation of the peptide backbone of glycoproteins in the superior colliculus (Fig. $7 A$ ) and biphasic turnover of fucose moieties on those glycoproteins (Fig. $7 \dot{B}$ ) can produce a biphasic accumulation of fucose radioactivity in the superior colliculus (Fig. $7 \mathrm{C}$ ). Thus, the first pulse-like wave of accumulation and decline of $\left[{ }^{3} \mathrm{H}\right]$ fucose radioactivity, which was thought to represent rapidly released and transported glycoproteins, is in a sense an artifact of the metabolic properties of the fucose moieties. The transport and accumulation of the peptide backbone of the glycoproteins are monophasic and involve commitment to rapid transport over a period of days.

This interpretation of the $\left[{ }^{3} \mathrm{H}\right]$ fucose-labeled glycoprotein transport data presented here is consistent with results concerning the rapid transport of other membrane constituents. In this interpretation, the rapid component of axonal transport is seen as consisting predominantly of a single cell body membrane pool which constantly supplies the axon and terminals. The time course of accumulation and decay of a specific labeled membrane macromolecule at the nerve endings is determined

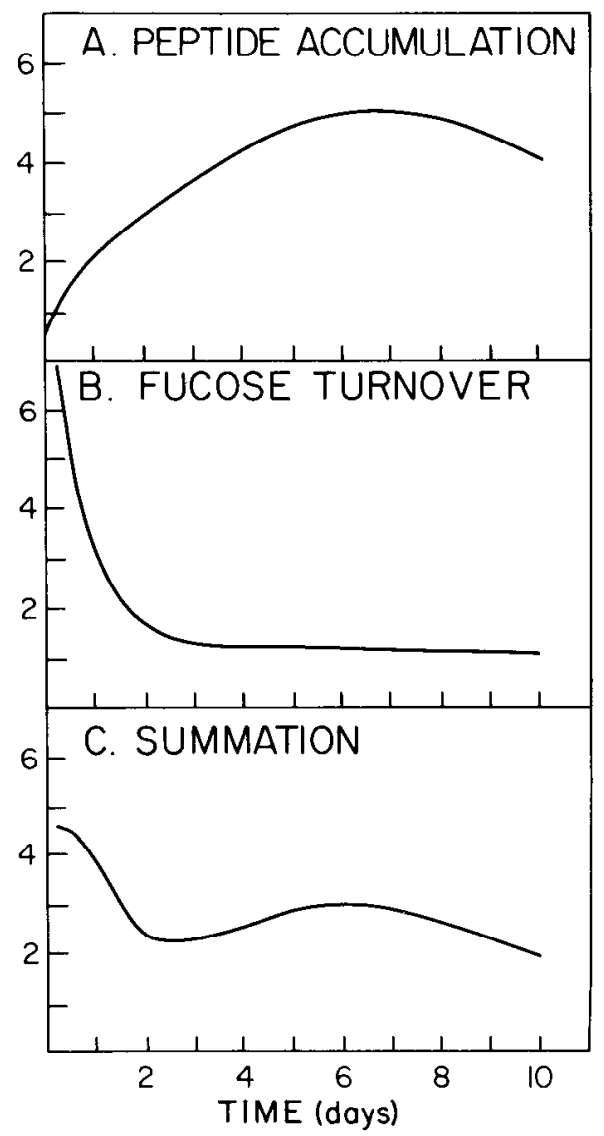

Figure 7. Hypothetical model curves describing transport and metabolism of fucosylated glycoprotein. A, Rapidly transported labeled glycoproteins accumulate for several days in the superior colliculus. We assume that this curve approximates the accumulation of the peptide backbone. $B$, The metabolic turnover of fucose in glycoproteins is biphasic. This curve approximates the actual turnover of fucose in the retina (see Fig. 1). $C$, The product of curves $A$ and $B$ (protein present $(A)$ $\times$ specific activity $(B)$ ) results in a biphasic accumulation $(C)$ of total fucose radioactivity in the superior colliculus.

by its metabolic turnover rate. A labeled molecule with a rapid turnover (e.g., the 100,000 - and 24,000 -dalton proteins; see "Results") will reach peak accumulation of radioactivity at the superior colliculus within a few hours or days and will then decline. Those radioactive molecules with longer half-lives, such as many of the glycoproteins (see "Results") and phospholipids (Haley et al., 1979; Toews et al., 1979), will accumulate in the superior colliculus for several days before starting to decline. A very stable molecule, such as cholesterol, will continue to accumulate for many weeks (Blaker et al., 1979). Note also that in this model (Fig. 7) the turnover of fucose moieties is the same or very similar whether the protein is in the cell body or the nerve ending.

'T'wo alternative explanations of the biphasic accumulation were considered and rejected. One was reutilization of the $\left[{ }^{3} \mathrm{II}\right]$ fucose. A report by Margolis and Margolis (1972) indicating little or no reutilization of $\left[{ }^{3} \mathrm{H}\right]$ fucose in brain due to loss of the tritium through exchange with water suggests that this is unlikely. The other alternative is the possibility of redistribution (exchange) of transported material along the axon. However, it has been 
previously shown (Goodrum and Morell, 1982) that there are only two specific glycoproteins deposited in the axons, while past (Goodrum and Morell, 1982) and present data show that the second accumulation of radioactivity contains a large complement of transported glycoproteins.

A limitation in our interpretation of the data is the heterogeneity of the system. There are many cell bodies involved, and axons differ in length. Comparison of labeled proteins at the nerve endings with those in the cell body is limited because of the large number of cell types in the retina (although it is noteworthy that much of the radioactive fucose is localized to the retinal ganglion cell layer at early times (Blanks, 1978)). Also, we could not test the hypothesis that there are several "waves" of transport in the first few hours, as has been shown by Ambron et al. (1974) in the giant neuron of Aplysia. However, even with these restrictions our interpretation of the data clarifies a long-standing puzzle in the literature. Why, following intraocular injection of the appropriate precursors, does radioactivity in fucosylated glycoproteins at the nerve endings peak within hours, a time when only a small fraction of the radioactive glycerophospholipid has accumulated? The expectation would have been that large amounts of phospholipid should accompany the fucosylated glycoprotein which is largely in particulate (membrane) fragments (see Schwartz, 1979, for review of evidence that particles destined for rapid transport are coordinately assembled). Our scheme (represented in Fig. 7 for proteins) suggests that the fucosylated glycoprotein is, in fact, committed to transport over a time course similar to that reported for phospholipids (Haley et al., 1979; Toews et al., 1979). A question remaining to be answered is whether the rapidly metabolized $\left[{ }^{3} \mathrm{H}\right]$ fucose moieties on glycoproteins are replaced with unlabeled fucose, or whether there is heterogeneity in terms of degree of fucosylation during the time course of commitment to transport and during transport itself.

\section{References}

Abe, T., T. Haga, and M. Kurokawa (1973) Rapid transport of phosphatidylcholine occurring simultaneously with protein transport in the frog sciatic nerve. Biochem. J. 136: 731-740.

Ambron, R. T., J. E. Goldman, and J. H. Schwartz (1974) Axonal transport of newly synthesized glycoproteins in a single identified neuron of Aplysia californica. J. Cell Biol. 61: 665-675.

Baitinger, C., J. Levine, T. Lorenz, C. Simon, P. Skene, and M. Willard (1982) Characteristics of axonally transported proteins. In Axoplasmic Transport, D. G. Weiss, ed., pp. 110120, Springer-Verlag, Berlin.

Baumann, H., and D. Doyle (1979) Localization of membrane glycoproteins by in situ neuraminidase treatment of rat hepatoma tissue culture cells and two-dimensional gel electrophoretic analysis of the modified proteins. J. Biol. Chem. 254: 2542-2550.

Baumann, H., and D. Doyle (1982) Turnover of plasma membrane glycoproteins and glycolipids (hepatoma as a model). In The Glycoconjugates, Vol. IV, pp. 105-153, Academic Press, New York.

Baumann, H., E. Hou, and G. P. Jahveis (1983) Preferential degradation of the terminal carbohydrate moiety of mem- brane glycoproteins in rat hepatoma cells and after transfer to the membranes of mouse fibroblasts. J. Cell Biol. 96: 139150.

Bennet, G., L. diGiamberardino, H. L. Koenig, and B. Droz (1973) Axonal migration of protein and glycoprotein to nerve ending. II. Radioautographic analysis of the renewal of glycoproteins in nerve endings of chicken ciliary ganglion after intracerebral injection of $\left[{ }^{3} \mathrm{H}\right]$ fucose and $\left[{ }^{3} \mathrm{H}\right]$ glucosamine. Brain Res. 60: 129-146.

Blaker, W. D., A. D. Toews, and P. Morell (1979) Cholesterol is a component of the rapid phase of axonal transport. J. Neurobiol. 11: 243-250.

Blaker, W. D., J. F. Goodrum, and P. Morell (1981) Axonal transport of the mitochondria-specific lipid, diphosphatidylglycerol, in the rat visual system. J. Cell Biol. 85: 575-584.

Blanks, J. C. (1978) Localization of $\left[{ }^{3} \mathrm{H}\right]$ glycoproteins in retina of the mouse. Brain Res. 152: 379-385.

Cleveland, D. W., S. G. Fischer, M. W. Kirschner, and U. K. Laemmli (1977) Peptide mapping by limited proteolysis in sodium dodecyl sulfate and analysis by gel electrophoresis. $\mathbf{J}$. Biol. Chem. 252: 1102-1106.

Goodrum, J. F., and P. Morell (1982) Axonal transport and metabolic turnover of glycoproteins in the rat optic pathway. J. Neurochem. 38: 696-704.

Goodrum, J. F., A. D. Toews, and P. Morell (1979) Axonal transport and metabolism of $\left[{ }^{3} \mathrm{H}\right]$ fucose- and $\left[{ }^{35} \mathrm{~S}\right]$ sulfatelabeled macromolecules in the rat visual system. Brain Res. 176: 255-272.

Grafstein, B., and D. S. Forman (1980) Intracellular transport in neurons. Physiol. Rev. 60: 1167-1283.

Haley, J. E., L. J. Tirri, and R. W. Ledeen (1979) Axonal transport of lipids in the rabbit optic system. J. Neurochem. 32: 727-734.

Karlsson, J. -O., and J. Sjostrand (1971) Synthesis, migration and turnover of proteins in retinal ganglion cells. J. Neurochem. 18: 749-767.

Kelly, A. S., J. A. Wagner, and R. B. Kelly (1980) Properties of individual nerve terminal proteins identified by two-dimensional gel electrophoresis. Brain Res. 185: 192-197.

Kreisel, W., B. A. Volk, R. Buchsel, and W. Reutter (1980) Different half-lives of the carbohydrate and protein moieties of a 110,000-dalton glycoprotein isolated from plasma membranes of rat liver. Proc. Natl. Acad. Sci. U. S. A. 77: 18281831.

Margolis, R. K., and R. U. Margolis (1972) Disposition of fucose in brain. J. Neurochem. 19: 1023-1030.

O'Farrell, P. Z., H. M. Goodman, and P. H. O'Farrell (1977) High resolution two-dimensional gel electrophoresis of basic as well as acidic proteins. Cell 12: 1133-1142.

Olden, K., J. B. Parent, and S. L. White (1982) Carbohydrate moieties of glycoproteins. A re-evaluation of their function. Biochim. Biophys. Acta 650: 209-232.

Padilla, S. S., and P. Morell (1980) Axonal transport of $\left[{ }^{3} \mathrm{H}\right]$ fucose-labeled glycoproteins in two intra-brain tracts of the rat. J. Neurochem. 35: 444-450.

Schwartz, J. H. (1979) Axonal transport: Components, mechanisms, and specificity. Annu. Rev. Neurosci. 2: 467-504.

Specht, S., and B. Grafstein (1977) Axonal transport and transneuronal transfer in mouse visual system following injection of $\left[{ }^{3} \mathrm{H}\right]$ fucose into the eye. Exp. Neurol. 54: 352-368.

Toews, A. D., and P. Morell (1981) Turnover of axonally transported phospholipids in nerve endings of retinal ganglion cells. J. Neurochem. 37: 1316-1326.

Toews, A. D., J. F. Goodrum, and P. Morell (1979) Axonal transport of phospholipids in rat visual system. .J. Neurochem. 32: 1165-1173.

Tytell, M., R. L. Gulley, R. J. Wenthold, and R. J. Lasek (1980) 
Fast axonal transport in auditory neurons of the guinea pig: A rapidly turned over glycoprotein. Proc. Natl. Acad. Sci. U. S. A. 77: 3042-3046.

Tytell, M., M. M. Black, J. A. Garner, and R. J. Lasek (1981) Axonal transport: Each major rate component reflects the movement of distinct macromolecular complexes. Science 214: 179-181.

Wagner, J. A., A. S. Kelly, and R. B. Kelly (1979) Nerve terminal proteins of the rabbit visual relay nuclei identified by axonal transport and two-dimensional gel electrophoresis. Brain Res. 168: 97-117.

Wenthold, R. J., and M. L. McGarvey (1982) Different polypeptides are rapidly transported in auditory and optic neurons. J. Neurochem. 39: 27-35.

Willard, M., W. M. Cowen, and P. R. Vagelos (1974) The polypeptide composition of intra-axonally transported proteins: Evidence for four transport velocities. Proc. Natl. Acad. Sci. U. S. A. 71: 2183-2187. 